\title{
PENGARUH PENERAPAN MODEL PEMBELAJARAN KONTEKSTUAL BERBANTUAN MEDIA FLASH TERHADAP PEMAHAMAN KONSEP FISIKA SISWA
}

\author{
Akbar Riyadi ${ }^{1}$, Gunawan ${ }^{2}$, Jannatin Ardhuha ${ }^{2}$ \\ 1) Program Studi Pendidikan Fisika \\ 2) Program Studi Pendidikan Fisika FKIP \\ Universitas Mataram \\ Mataram, Indonesia \\ Email : akbar.riyadi71@gmail.com
}

\begin{abstract}
This research is a quasy experiment which aimed to finding out the effect of contextual learning model implementation assisted by media flash on the understanding concept of physics in SMPN 1 Labuapi. The population is all class VIII which filled by 117 students, while the sample of this research is class VIII B with 23 students as experiment group and grade VIII C with 23 students as control group. The sampling technique used is purposive sampling. The research design used is nonequivalent control group design. The hypothesis is tested by ttest separated varians. Based on by calculation hypothesis testing obtained that there is a difference of understanding concept of physics between experiment group which is given treatment with contextual learning model assisted by media flash and control group which is given treatment as convensional learning. The mean of the posttest for experiment group is greater than control group, so it can be obtained that contextual learning model assisted by media flash given positive result for understanding concept of physics in grade VIII SMPN 1 Labuapi. N-gain test given that for all of sub materi of light showed that the increasing of understanding concept of physics of class experiment is higher than control class, so it can be obtained that the increasing of understanding concept of physics of experiment group is higher than control group.
\end{abstract}

Keywords: contextual learning model, media flash, understanding concept of physics.

\section{PENDAhUluan}

IPA pada hakikatnya merupakan sebuah kumpulan pengetahuan (a body of knowledge), cara berpikir ( $a$ way of thinking), dan cara penyelidikan (a way of investigating). IPA sebagai kumpulan pengetahuan merupakan hasil-hasil penemuan dari berbagai kegiatan penyelidikan yang kreatif dari para ilmuwan yang dikumpulkan dan disusun secara sistematik yang disebut sebagai produk berupa fakta, konsep, prinsip, hukum, rumus, teori, dan model. IPA sendiri terdiri dari tiga bidang ilmu dasar yaitu fisika, biologi, dan kimia.

Fisika merupakan salah satu cabang dari IPA dan merupakan ilmu pengetahuan yang mempelajari gejalagejala alam melalui serangkaian proses ilmiah. Proses ilmiah ini dibangun atas dasar sikap ilmiah dan hasilnya terwujud sebagai produk ilmiah yang tersusun atas tiga komponen terpenting berupa konsep, prinsip, dan teori yang berlaku secara universal [1]. Konsep merupakan batu-batu pembangun (building block) berpikir. Konsepkonsep dasar dipelajari untuk membentuk proses-proses mental yang lebih tinggi untuk merumuskan prinsipprinsip dan generalisasi-generalisasi [2]. Dalam pembelajaran fisika, kemampuan memahami konsep merupakan syarat mutlak dalam mencapai keberhasilan pembelajaran fisika. Untuk memecahkan masalah, seorang siswa harus mengetahui aturan-aturan yang relevan, dan aturan-aturan ini didasarkan pada konsepkonsep yang diperolehnya.

Hasil observasi yang dilakukan peneliti di SMPN 1 Labuapi menunjukkan bahwa pembelajaran fisika di sekolah ini cenderung bersifat informatif atau hanya berupa transfer pengetahuan dari guru ke siswa tanpa melibatkan kegiatan untuk menunjukkan mengapa pengetahuan tersebut penting untuk dipelajari. Guru jarang mengaitkan antara konsep fisika dengan aplikasinya dalam kehidupan sehari-hari. Hal tersebut menyebabkan siswa tidak merasakan manfaat dari belajar fisika dan menyebabkan siswa kurang antusias dalam mempelajari fisika. Siswa hanya mengetahui bahwa fisika hanya pelajaran yang berisi rumus-rumus 
serta teori, tanpa tahu bagaimana menerapkannya dalam kehidupan sehari-hari. Siswa hanya diberikan pemahaman langsung terhadap materi tanpa melalui proses pembentukan pemahaman konsep dalam diri siswa, sehingga siswa tidak memahami konsep fisika yang mereka pelajari. Hal ini tentunya akan berdampak terhadap hasil belajar siswa. Hasil belajar IPA fisika siswa kelas VIII tergolong rendah dan di bawah standar ketuntasan belajar yang ditetapkan, yaitu 70 .

Berdasarkan kenyataan di atas, diperlukan sebuah model pembelajaran yang dapat meningkatkan pemahaman konsep fisika siswa. Salah satu model pembelajaran yang dapat diterapkan ialah model pembelajaran kontekstual (contextual teaching and learning). Pembelajaran kontekstual adalah konsep belajar yang membantu guru mengaitkan antara materi yang diajarkan dengan situasi dunia nyata siswa dan mendorong siswa membuat hubungan antara pengetahuan yang dimilikinya dengan penerapannya dalam kehidupan sehari-hari [1]. Model pembelajaran kontekstual cocok diterapkan dalam pembelajaran fisika yang konsep-konsep fisikanya sangat dekat dengan kehidupan siswa, misalnya pada materi cahaya.

Materi cahaya merupakan materi yang konsep fisikanya abstrak sehingga sulit dipahami oleh siswa SMP. Oleh karena itu, peneliti menggunakan media pembelajaran untuk mendampingi model pembelajaran kontekstual agar pembelajaran lebih menarik dan penyampaian informasi yang lebih jelas. Asyhar mengungkapkan bahwa media pembelajaran mampu membuat pembelajaran lebih menarik (joyfull learning), pesan dan informasi menjadi lebih jelas, serta mampu memanipulasi dan menghadirkan objek yang sulit dijangkau oleh peserta didik [3].

\section{Tinjauan Pustaka}

\section{A. Model Pembelajaran Kontekstual}

Rusman mengatakan bahwa model pembelajaran kontekstual adalah sebuah sistem yang merangsang otak untuk menyusun pola-pola yang mewujudkan makna. Lebih lanjut, pembelajaran kontekstual adalah suatu sistem pembelajaran yang cocok dengan otak yang menghasilkan makna dengan menghubungkan muatan akademis dengan konteks kehidupan sehari-hari [4].

Pembelajaran kontekstual dilandasi oleh 7 teori-teori belajar, yaitu: teori belajar konstruktivisme, teori perkembangan kognitif piaget, metode pengajaran John
Dewey, teori pemrosesan informasi, teori bermakna David Ausubel, teori penemuan Jerome Bruner, dan teori pembelajaran sosial Vygotsky [1]. Secara garis besar langkah-langkah penerapan pembelajaran kontekstual dalam kelas sebagai berikut:

Tabel 1. Sintaks Model Pembelajaran Kontekstual

\begin{tabular}{|c|c|}
\hline Tahapan & Peran Guru \\
\hline $\begin{array}{l}\text { Menyampaikan dan } \\
\text { mempersiapkan } \\
\text { siswa } \\
\text { Menggali } \\
\text { pengetahuan awal }\end{array}$ & $\begin{array}{l}\text { Guru menyampaikan tujuan } \\
\text { pembelajaran dan } \\
\text { memberikan motivasi belajar. } \\
\text { Guru memberikan beberapa } \\
\text { contoh penerapan konsep } \\
\text { yang kontekstual dan } \\
\text { merupakan peristiwa yang } \\
\text { umum dijumpai siswa dalam } \\
\text { kehidupan sehari-hari. Guru } \\
\text { menanyakan pendapat siswa } \\
\text { mengenai contoh peristiwa } \\
\text { yang diberikan. }\end{array}$ \\
\hline Memberikan latihan & $\begin{array}{l}\text { Guru memberikan latihan dan } \\
\text { membimbing siswa secara } \\
\text { berkelompok. }\end{array}$ \\
\hline $\begin{array}{l}\text { Mengecek } \\
\text { pemahaman }\end{array}$ & $\begin{array}{l}\text { Guru mengecek apakah siswa } \\
\text { sudah memahami materi atau } \\
\text { belum dan memberikan } \\
\text { bantuan kepada siswa yang } \\
\text { belum memahami materi. }\end{array}$ \\
\hline $\begin{array}{l}\text { Memberikan } \\
\text { penilaian }\end{array}$ & $\begin{array}{l}\text { Guru memberikan penilaian } \\
\text { sesuai dengan hasil yang } \\
\text { dicapai siswa. }\end{array}$ \\
\hline
\end{tabular}

\section{B. Media Flash}

Media yang digunakan dalam penelitian ini dibuat dengan program macromedia flash 8. Macromedia Flash 8 merupakan salah satu program pembuatan animasi yang fleksibel dalam pembuatan animasi interaktif, game, company profile, presentasi, movie, dan tampilan animasi lainnya [5]. Media pembelajaran yang dibuat dengan macromedia flash 8 ini meliputi tiga jenis media, yakni gambar, video, dan animasi. Media ini digunakan untuk menjelaskan konsep-konsep fisika tentang materi cahaya yang terbagi dalam tiga sub materi, yaitu sifat-sifat cahaya, pemantulan cahaya dan pembiasan cahaya. Langkah-langkah pembuatan media ini sebagai berikut:

1. Membuat storyboard dari media pembelajaran yang dibuat.

2. Menyiapkan gambar, video dan animasi yang akan digunakan dalam pembuatan media. 
3. Membuat halaman utama sebagai tampilan awal media beserta tombol-tombol yang menghubungkan langsung ke halaman-halaman sub materi.

4. Membuat halaman-halaman untuk ketiga sub materi sesuai dengan langkah-langkah pembelajaran yang telah dirancang dalam RPP.

5. Validasi media oleh validator media sebelum digunakan dalam penelitian.

6. Mengkonversi media menjadi aplikasi (*.exe).

\section{Pemahaman Konsep}

Konsep adalah suatu abstraksi yang mewakili satu kelas objek, kejadian, kegiatan, atau hubungan yang mempunyai atribut yang sama [2]. Konsep berwujud sebagai pengertian-pengertian baru yang dapat timbul sebagai hasil pemikiran, meliputi definisi, pengertian, ciri khusus, hakekat, inti atau isi dan sebagainya.

Pemahaman konsep didefinisikan sebagai kemampuan siswa dalam memahami suatu abstraksi yang menggambarkan karakteristik konsep secara ilmiah, baik secara teori maupun penerapannya dalam kehidupan sehari-hari yang dapat dilihat dari tes awal dan tes akhir.

\section{Metode Penelitian}

Penelitian ini dilaksanakan pada kelas VIII SMPN 1 Labuapi tahun pelajaran 2013/2014. Jenis penelitian ini adalah kuasi eksperimen. Desain penelitian menggunakan nonequivalent control group design. Adapun teknik pengambilan sampel yang digunakan adalah purposive sampling. Sampel pada penelitian ini adalah siswa kelas VIII B sebagai kelas eksperimen dan siswa kelas VIII C sebagai kelas kontrol.

Dalam penelitian ini terdapat tiga variabel yang menjadi fokus penelitian yaitu variabel bebas, variabel kontrol, dan variabel terikat. Variabel bebas pada penelitian ini adalah model pembelajaran, variabel terikat berupa pemahaman konsep fisika siswa, dan variabel kontrol berupa kemampuan awal kelas eksperimen dan kelas kontrol yang dipilih sama (homogen), guru, materi, tujuan pembelajaran, instrumen tes pemahaman konsep fisika, dan cara penilaian. Teknik pengumpulan data pada penelitian ini adalah tes pemahaman konsep fisika siswa. Data pemahaman konsep fisika siswa merupakan data tes pemahaman konsep yang dilakukan sebelum dan setelah perlakuan. Data tes awal dan tes akhir pemahaman konsep fisika siswa diperoleh dengan menggunakan instrumen yang telah diujicobakan kepada 19 orang siswa kelas VIII di SMPN 3 Mataram tahun ajaran 2013/2014 yang diukur dengan uji validitas, reliabilitas, tingkat kesukaran, dan daya beda soal. Berdasarkan hasil uji coba 35 butir soal diperoleh 25 soal yang baik digunakan untuk tes awal dan tes akhir. Analisis validitas instrumen menggunakan rumus product moment untuk menguji validitas soal dan rumus Spearmen-Brown untuk uji reliabilitas soal. Analisis data tes akhir menggunakan uji-t dua pihak. Peningkatan pemahaman konsep fisika siswa pada kedua kelas ditentukan dengan rumus uji $\mathrm{N}$-Gain ternormalisasi.

\section{Hasil dan Pembahasan}

Media pembelajaran yang digunakan dalam penelitian ini melibatkan 3 komponen, yakni video, gambar, dan animasi. Video dan gambar yang digunakan dalam media ini, diambil dari berbagai sumber. Sedangkan animasi yang ada dalam media ini dibuat oleh peneliti. Sebelum penelitian dilaksanakan, media flash dinilai oleh validator media untuk menentukan kelayakan media tersebut ketika digunakan dalam penelitian. Berdasarkan hasil penilaian tersebut, validator media memutuskan bahwa media pembelajaran yang dibuat layak digunakan dalam penelitian.

Berdasarkan analisis data penilaian pemahaman konsep fisika siswa, dapat diketahui adanya peningkatan pemahaman konsep fisika siswa pada kedua kelas (kelas eksperimen dan kelas kontrol). Hasil penilaian ini kemudian dihitung dengan rumus $\mathrm{N}$-Gain ternormalisasi untuk mengetahui peningkatan pemahaman konsep fisika siswa pada kedua kelas. Perolehan pemahaman konsep fisika siswa dapat dilihat pada Tabel 2.

Tabel 2. Rekapitulasi Data Pemahaman Konsep Fisika Siswa pada Kedua Kelas

\begin{tabular}{lccc}
\hline Kelas & $\begin{array}{c}\text { Nilai Rata- } \\
\text { Rata Tes } \\
\text { Awal }\end{array}$ & $\begin{array}{c}\text { Nilai Rata- } \\
\text { Rata Tes } \\
\text { Akhir }\end{array}$ & N-gain \\
\hline Eksperimen & 32,20 & 68,78 & $52 \%$ \\
Kontrol & 29,45 & 47,11 & $13 \%$ \\
\hline
\end{tabular}

Data pada tabel 2 menunjukkan bahwa nilai rata-rata tes awal siswa pada kedua kelas hampir sama. Hasil uji beda rerata pada skor tes awal menunjukkan nilai $\boldsymbol{t}_{\text {hitung }}$ sebesar 1,50 dan $\boldsymbol{t}_{\text {tabel }}$ pada taraf kepercayaan 0,05 sebesar 2,66. Berdasarkan hasil ini dapat 
disimpulkan bahwa pemahaman konsep fisika siswa pada kedua kelas sebelum permbelajaran adalah sama.

Selanjutnya berdasarkan data tes akhir pemahaman konsep fisika siswa pada kedua kelas, diketahui bahwa nilai rata-rata tes akhir kelas eksperimen sebesar 68,78 dan kelas kontrol sebesar 47,11. Hasil uji t menunjukkan nilai $\boldsymbol{t}_{\text {hitung }}$ sebesar 8,63 dan $\boldsymbol{t}_{\text {tabel }}$ pada taraf kepercayaan 0,05 sebesar 2,03. Hal ini berarti terdapat perbedaan pemahaman konsep fisika siswa menggunakan model pembelajaran kontekstual berbantuan media flash dengan pembelajaran konvensional pada siswa SMPN 1 Labuapi tahun pelajaran 2013/2014. Selanjutnya, dilakukan uji N-Gain ternormalisasi pada kedua kelas untuk mengetahui perbedaan peningkatan pada kedua kelas. Berdasarkan hasil perhitungan $\mathrm{N}$-Gain pada kedua kelas, diperoleh bahwa peningkatan pemahaman konsep fisika siswa pada kelas eksperimen sebesar 52\% sedangkan pada kelas kontrol sebesar 13\%. Hasil perhitungan $N$-Gain ini menunjukkan bahwa peningkatan pemahaman konsep fisika siswa pada kelas eksperimen lebih tinggi dibandingkan dengan kelas kontrol.

Model pembelajaran kontekstual mampu mengkonstruksi pemahaman konsep fisika siswa. Hal ini dikarenakan contoh-contoh penerapan materi yang diberikan merupakan peristiwa sehari-hari yang sering diamati oleh siswa. Konsep fisika tidak sulit dibentuk dalam diri siswa karena model pembelajaran ini mengakrabkan siswa pada konsep tersebut.

Berdasarkan dari hasil pengamatan peneliti selama proses pembelajaran berlangsung, terlihat bahwa perlakuan yang diberikan oleh peneliti pada kelas ekperimen membuat siswa lebih aktif dalam belajar dan meningkatkan pemahaman konsep fisika siswa. Hal ini dikarenakan bahwa pada model pembelajaran kontekstual, siswa diarahkan dan dibimbing untuk lebih aktif menemukan konsep fisika dari peristiwa yang terjadi di kehidupan sehari-harinya. Siswa merasa bahwa mereka membutuhkan materi yang dijelaskan untuk menjawab rasa keingintahuan mereka sehingga mereka belajar dengan kesadaran penuh. Sedangkan pada media pembelajaran media flash, peneliti telah merancang tampilan gambar, video, animasi yang ringan, menarik, dan mudah dipahami oleh siswa sehingga mendukung model pembelajaran kontekstual itu sendiri dalam menyampaikan konsep-konsep cahaya.
Konsep cahaya merupakan konsep yang abstrak. Penerapan konsep cahaya hanya bisa dilihat hasil akhirnya, namun prosesnya tidak dapat dilihat secara langsung karena kecepatan cahaya yang sangat tinggi. Oleh karenanya, peran media animasi dalam menjelaskan konsep cahaya ini sangat membantu siswa dalam membentuk konsep dalam dirinya. Berdasarkan uraian tersebut, dapat disimpulkan bahwa penerapan model pembelajaran kontekstual berbantuan media flash dalam proses pembelajaran, terbukti dapat meningkatkan pemahaman konsep fisika siswa lebih besar daripada pembelajaran konvensional.

Peningkatan pemahaman konsep fisika siswa juga dapat diamati pada tiap-tiap sub materi. Pada sub materi sifat-sifat cahaya, peningkatan pemahaman konsep fisika siswa pada kelompok kontrol sebesar $27 \%$ sedangkan untuk kelas ekperimen sebesar $53 \%$. Peningkatan yang terjadi pada kedua kelompok cukup besar dan terlihat pula bahwa kelompok eksperimen lebih unggul dibandingkan kelompok kontrol. Hal ini dikarenakan bahwa sub materi sifat-sifat cahaya yang diajarkan pada kelas eksperimen, dijelaskan secara kontekstual dan dibantu dengan media flash. Penggunaan media flash yang menampilkan beberapa contoh aplikasi umum mengenai cahaya dalam bentuk gambar dapat mempermudah siswa dalam memahami sifat-sifat cahaya sehingga peningkatan pemahaman konsep fisika siswa pada kelas eksperimen lebih tinggi daripada peningkatan pada kelas kontrol yang menerapkan pembelajaran konvensional.

\section{PenutuP}

Berdasarkan hasil penelitian dan pembahasan maka dapat disimpulkan bahwa terdapat perbedaan pemahaman konsep fisika siswa antara kelas eksperimen yang diberikan perlakuan menggunakan model pembelajaran kontekstual berbantuan media flash dengan kelas kontrol yang diberikan perlakuan berupa pembelajaran konvensional pada siswa kelas VIII SMPN 1 Labuapi tahun pelajaran 2013/2014. Dari perbedaan tersebut, dapat disimpulkan bahwa ada pengaruh penerapan model pembelajaran kontekstual berbantuan media flash terhadap pemahaman konsep fisika siswa. Dari perhitungan nilai rata-rata pada tes akhir diperoleh bahwa nilai rata-rata yang diperoleh kelas eksperimen lebih tinggi daripada kelas kontrol, sehingga dapat disimpulkan bahwa penerapan model pembelajaran kontekstual berbantuan media flash 
berpengaruh positif terhadap pemahaman konsep fisika pada siswa. Dari perhitungan $\mathrm{N}$-Gain ternormalisasi secara keseluruhan dan per sub materi pada kedua kelas, dapat disimpulkan bahwa peningkatan pemahaman konsep fisika siswa pada tiap sub materi cahaya pada kelas eksperimen yang menggunakan model pembelajaran kontekstual berbantuan media flash lebih tinggi dibandingkan dengan kelas kontrol yang menggunakan pembelajaran konvensional.

Agar memperoleh hasil yang lebih baik maka perlu diadakan perbaikan dalam menggunakan model pembelajaran kontekstual berbantuan media flash. Misalnya dengan mengatur kesiapan siswa sebelum kegiatan pembelajaran atau pengelolaan kelas alokasi sebaik mungkin.

\section{REFERENSI}

[1] Trianto. 2008. Mendesain Pembelajaran Kontekstual (Contextual Teaching and Learning) di Kelas. Jakarta: Cerdas Pustaka Publisher.

[2] Dahar, R, W. 1988. Teori-Teori Belajar. Bandung: Erlangga.

[3] Asyhar, R. 2012. Kreatif Mengembangkan Media Pembelajaran. Jakarta: Referensi.

[4] Rusman. 2010. Model-Model Pembelajaran Fisika. Jakarta: Rajawali Pers.

[5] Rosari, R, W. 2007. Macromedia Flash Pro 8. Yogyakarta: Penerbit ANDI.

\section{Biografi Penulis}

Akbar Riyadi, lahir di Sukmajaya, Depok, 26 Januari 1992. Tahun 2004 lulus di SDN Pabuaran 1, Cibinong, Bogor, dan tahun 2007 lulus dari SMPN 1 Sape, Bima. Tahun 2010 lulus dari SMAN 1 Sape dan melanjutkan pendidikan S-1 di Universitas Mataram pada program studi pendidikan fisika hingga meraih gelar sarjana tahun 2014. 